\title{
STABLE ISOTOPES IN TREE RINGS AS PROXIES FOR WINTER PRECIPITATION CHANGES IN THE RUSSIAN ARCTIC OVER THE PAST 150 YEARS
}

\author{
STEFFEN HOLZKÄMPER ${ }^{1}$, PETER KUHRY ${ }^{1}$, SEIJA KULTTI ${ }^{2}$, \\ BJÖRN GUNNARSON ${ }^{1}$ and ELONI SONNINEN ${ }^{3}$ \\ ${ }^{I}$ Department of Physical Geography and Quaternary Geology, Stockholm University \\ 10691 Stockholm, Sweden \\ ${ }^{2}$ Department of Geology, University of Helsinki \\ P.O.Box 64, Gustaf Hällströmin katu 2a, FI-00014 University of Helsinki, Finland \\ ${ }^{3}$ Radiocarbon Dating Laboratory, University of Helsinki \\ P.O.Box 64, Gustaf Hällströmin katu 2a, FI-00014 University of Helsinki, Finland
}

Received 22 October 2008

Accepted 18 December 2008

\begin{abstract}
We present results from an analysis of tree ring width and stable carbon and oxygen isotopes in tree ring cellulose of Siberian Spruce collected from remote forest islands in the northwestern Russian tundra. Ring width is often considered a proxy for summer temperatures. The aim of this pilot study was to test whether stable isotopes can provide additional information about climate during the growth of trees in this extreme environment. Comparison of $\delta^{13} \mathrm{C}$ and $\delta^{18} \mathrm{O}$ with observed meteorological data shows that there is a link between stable isotopes and winter precipitation. This may be explained by the strong influence that snow exerts on the isotopic composition of soil moisture during spring and early summer, when the new cellulose is formed. Our results show that winter precipitation in the study area was increasing from 1865-1900, and thereafter decreasing until $\sim 1930$. The 1960-1980 period was again rather humid, followed by a drying trend until 1990. The study highlights the potential of stable carbon and oxygen isotopes in tree rings as proxies for winter precipitation.
\end{abstract}

Keywords: tree rings; stable isotopes; Russian Arctic.

\section{INTRODUCTION}

There is generally a large paucity of past climate data from the Russian Arctic. Studies that aim to investigate tree growth conditions at the arctic tree line over time can be very useful to shed light on the climate conditions prior to the period of instrumental record. According to recent climate model simulations, future climate changes in the Arctic will be more rapid and pronounced than the global average. This would have severe consequences for the local environment and, because of feedback processes, also for global climate (Harding et al., 2002). It is of great importance to understand past changes in arctic climate in order to assess ecosystem responses and fore-

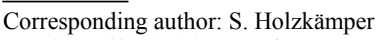

e-mail: steffen.holzkamper@natgeo.su.se

ISSN 1897-1695 (online), 1733-8387 (print) (C) 2008 GADAM Centre, Institute of Physics, Silesian University of Technology.

All rights reserved. see the magnitude of feedback processes in the future (IPCC, 2007).

Earlier dendroclimatological studies have shown that there are large spatial differences in the seasonal temperature changes over the past 2000 years across northwestern Eurasia (Briffa et al., 2008). According to a study from the eastern flank of the northern Urals, there was a pronounced increase in summer temperatures at the end of the $19^{\text {th }}$ and beginning of the $20^{\text {th }}$ century that was remarkably different from reconstructions in northern Fennoscandia, where no such warming could be observed (Briffa, 1995). Thus, there is a need to get a more detailed picture of the spatial extent and nature of past climate variability in northwestern Eurasia. Furthermore, there is large uncertainty how precipitation has changed in the past and how it will change in the future. Stable isotopes in tree rings can help to shed more light on these questions. They can contribute to our understanding of climate 
dynamics as they add annually resolved data that can be interpreted in terms of paleoclimatic and paleoenvironmental conditions during the growth of the trees (McCarroll and Loader, 2004).

The aim of this study is to test whether stable oxygen and carbon isotopes in ring cellulose collected from tree samples in remote forest islands in the lowland tundra west of the Ural Mountains can be used as proxies for annual and decadal variability in temperature and precipitation.

\section{STUDY AREA AND MATERIALS}

The Moreju River catchment, which drains into the Barents Sea, is situated in the northernmost part of the northeastern European Russian lowlands, in the Nenets Autonomous District of the Arkhangelsk Region (Fig. 1). The area is underlain by Quaternary sediments and is

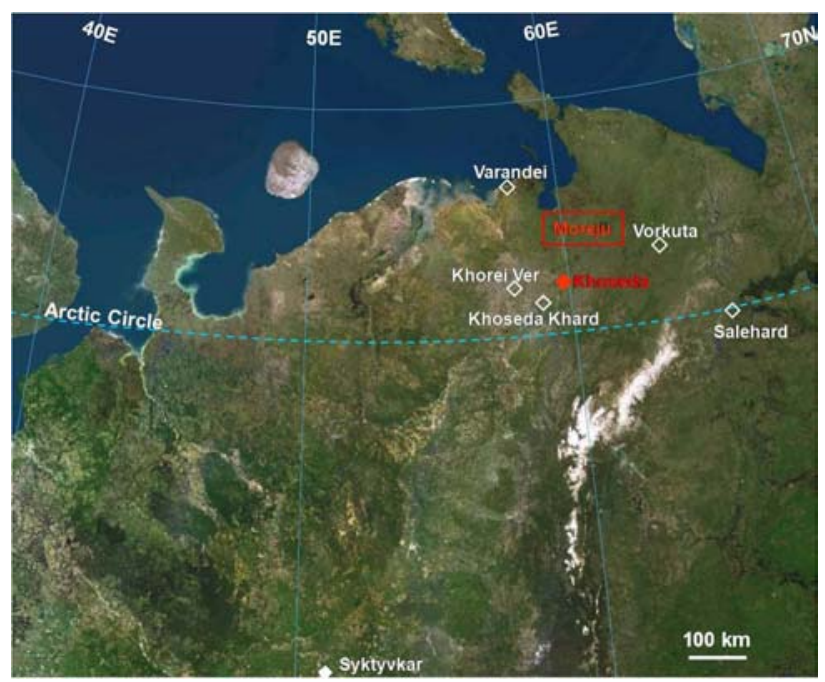

Fig. 1. Study area. The catchment of the Moreju River is indicated in red, also the additional site at Khosedayu River. Surrounding weather stations are indicated as white, open diamonds. located in the transition zone of the continuous to discontinuous permafrost zones. It can be described as lowland tundra dominated by wetland vegetation, willow bushes, dwarf shrubs and lichens. The climate in the study area is arctic, with mean annual temperatures of around -4.9 to $-5.9^{\circ} \mathrm{C}$ and an annual precipitation of 400 to $480 \mathrm{~mm}$.

The river valley is cut into the lowland plain and the height difference between the water level and the plain is about 5 to $20 \mathrm{~m}$. The site where the Siberian Spruce (Picea abies ssp. obovata) samples T1, T2, T3 and T4 were collected is a particularly deep valley incision, at $\sim 80 \mathrm{~km}$ distance from the Barent's Sea coast $\left(68.1^{\circ} \mathrm{N}\right.$, $60.0^{\circ} \mathrm{E}$; elevation $\sim 40 \mathrm{~m}$ a.p.s.1.). Here, small forest patches with up to $10-12 \mathrm{~m}$ tall trees are able to grow $\sim 150 \mathrm{~km}$ north of the forest limit proper (Fig. 2), due to the absence of (near surface) permafrost near the river banks and the more favourable microclimatic conditions (e.g. wind protection).

Trees T1 and T2 were collected from a high and steep riverbank, whereas trees T3 and T4 were growing on a terrace sloping more gently into the present alluvial plain (Fig. 2). Tree T5 was a dead trunk lying on the present alluvial plain some $\sim 20 \mathrm{~km}$ downstream from the forest island. An additional tree from a site $\sim 100 \mathrm{~km}$ south of the Moreju site was included in this study. This tree was collected on the upper terrace of the Khoseda River $\left(67.2^{\circ} \mathrm{N}, 59.5^{\circ} \mathrm{E}, \sim 90 \mathrm{~m}\right.$ a.p.s.l., Fig. 1).

\section{METHODS}

The primary source of climate data is the records from the Russian Hydrometeorological Service.

Four tundra climate stations lie within the larger vicinity $(<150 \mathrm{~km}$ distance) of the Moreju study site, i.e. the meteorological stations of Khoseda Khard, Varandei, Khorei-Ver and Vorkuta. The longest of these records, Khoseda Khard, started in 1932. Another tundra climate station relevant for this study is Salekhard that lies $\sim 300 \mathrm{~km}$ east of the Moreju study site, on the eastern foothills of the Ural Mountains. There, the measurements

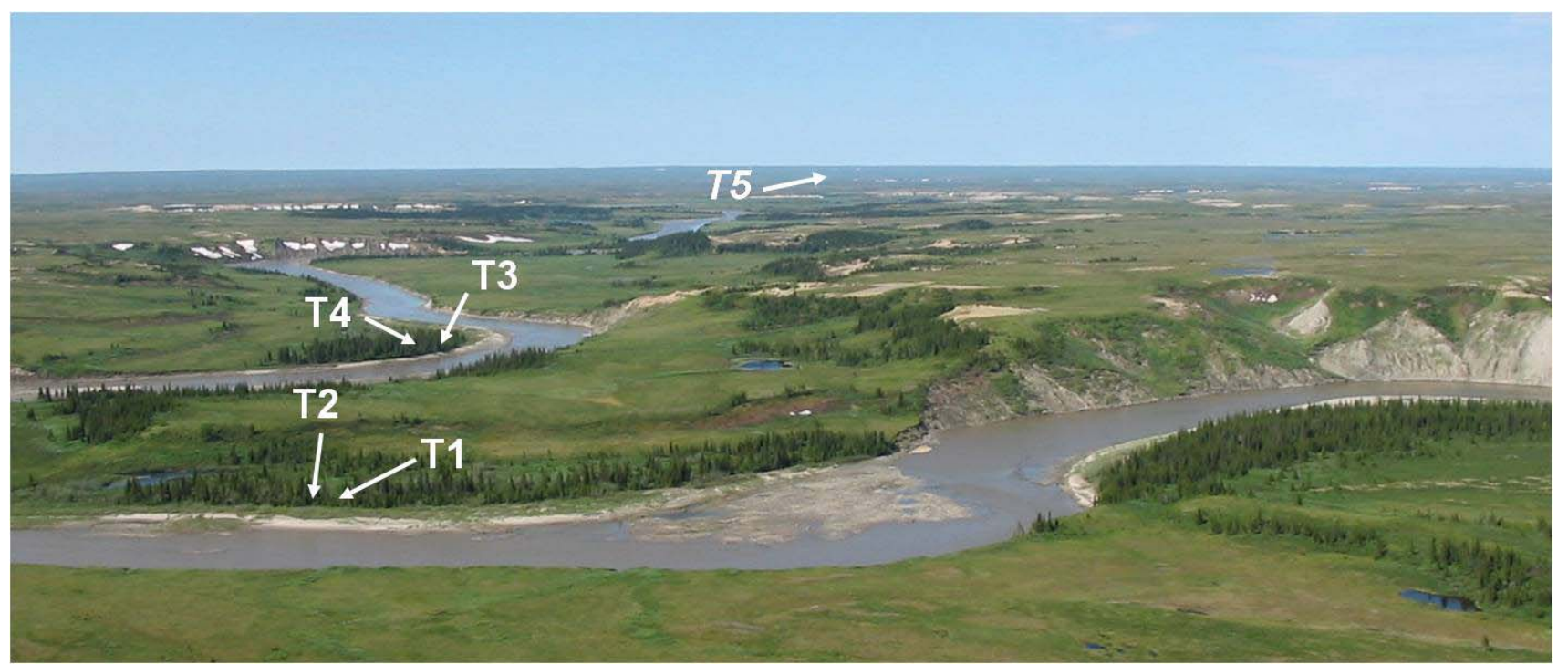

Fig. 2. Forest patches along the Moreju River where the investigated trees $T 1$ to $T 4$ were retrieved. Tree $T 5$ was collected a few $\mathrm{km}$ downstream. 
started in 1883. In addition, another five taiga meteorological stations located to the South of Moreju are of interest to integrate the record of observed climatic conditions in the region. Measured parameters and covered time periods are summarized in Table 1. The climate data used for calculating the correlation coefficients for the Moreju samples is the mean from available observations from one to four meteorological stations and for the Khoseda samples from the nearby Khoseda-Khard station.

The tree species studied is Siberian Spruce (Picea abies ssp. obovata). Five tree discs were collected during a field trip in summer 2004, labelled T1, T2, T3, T4 and $\mathrm{T} 5$; the tree from Khoseda area was collected in summer 1998. T3 was disregarded because of rotten segments which rendered precise ring counting, measuring and sampling impossible.

Ring width measurements were carried out with an accuracy of $0.01 \mathrm{~mm}$ on two to three radii on each disc and an average growth curve for each disc was calculated. After comparison of ring width curves from the different trees we decided to include trees T1, T2 and T5 for the calculation of the Moreju index only and to omit the data from T3 and T4. T3 had rotten segments and T4 showed a heavily disturbed ring-width pattern that, however, could still be cross-matched to the Morejuchronology. The Khoseda-index was calculated from 33 radii measured on 16 trees. To remove the agedependent trend and non-climatic related trends in the chronology, an exponential curve was fitted to the raw width data and this trend was deducted from the original data. This process is known as standardization. All treering series included in the final chronologies were quality checked, both visually and using the COFECHA software (Holmes et al., 1986), which verified cross dating among tree-ring series. The retrieved Moreju chronology was compared to Shchely Bozh $\left(66^{\circ} \mathrm{N}, 56^{\circ} \mathrm{E}\right)$, simply called "Russian chronology" in the further text, obtained from the International Tree-Ring Data Bank (ITRDB, www.ngdc.noaa.gov/paleo/treering.html) collected by F. Schweingruber and colleagues in the 1990 s to verify correct cross-dating.
T2, T4 and T5 were analyzed for stable carbon and oxygen isotopes; Khoseda was analyzed for stable carbon isotopes only. The wood from single tree rings was cut from the discs with a surgery knife. About 10 to $200 \mathrm{mg}$ of wood was used for the alpha-cellulose extraction following the method described in Loader et al., 1997. Isotope ratios of cellulose samples for carbon isotope ratio were analyzed on a continuous-flow isotope ratio mass spectrometer (Delta Advantage, Thermofinnigan, Germany) and an elemental analyzer (NC2500, Carlo Erba, Italy), and for oxygen isotope ratio on a continuous-flow isotope mass spectrometer (Delta Advantage or Delta $+X L$, Thermofinnigan, Germany) and a hightemperature elemental analyzer (TC/EA , Thermo Fisher, Germany). The ${ }^{13} \mathrm{C} /{ }^{12} \mathrm{C}$ and ${ }^{18} \mathrm{O} /{ }^{16} \mathrm{O}$ ratios are expressed in the delta $(\delta)$ convention in parts per thousand (\%o) relative to VPDB for carbon and VSMOW for oxygen as follows:

$$
\delta X=\left(R_{\text {sample }} / R_{\text {std }}-1\right) \times 1000
$$

where $\mathrm{X}$ is ${ }^{13} \mathrm{C}$ or ${ }^{18} \mathrm{O}$ and $\mathrm{R}$ is the corresponding isotope ratio.

Precision, as determined by multiple measurements of the reference samples, is better than $0.1 \%$ for $\delta^{13} \mathrm{C}$, and $0.3 \%$ for $\delta^{18} \mathrm{O}$.

The correlations between the resulting tree ring index, $\delta^{18} \mathrm{O}, \delta^{13} \mathrm{C}$ and observed monthly air temperature and precipitation have been calculated using the statistics program SPSS and the tree ring software DENDROCLIM2002 (Biondi and Waikul, 2004).

\section{RESULTS}

\section{Observed climate}

The mean annual temperatures and precipitation of four nearby tundra weather stations are highly correlated (Fig. 3). Thus it can be assumed, that the climate conditions at the Moreju River study site were similar to those measured at the stations, especially as there is hardly any topographical unevenness in the region. A comparison between the average annual temperature anomalies (de-

Table 1. Overview of available climate data from four stations in the vicinity of the study area and Salekhard (tundra) and five stations in the taiga, with time period of observed parameters ("s.g." means small gaps in the data set; "b.g." means big gaps in the data set).

\begin{tabular}{|c|c|c|c|c|c|c|}
\hline Station name & $\begin{array}{c}\text { Latitude } \\
\text { (“.') }\end{array}$ & $\begin{array}{l}\text { Longitude } \\
\text { (“'.) }\end{array}$ & $\begin{array}{l}\text { Altitude } \\
\text { (m) }\end{array}$ & Type of landscape & $\begin{array}{l}\text { Period of analyzed } \\
\text { monthly mean temp }\end{array}$ & $\begin{array}{l}\text { Period of ana- } \\
\text { lyzed monthly } \\
\text { precipitation }\end{array}$ \\
\hline \multicolumn{7}{|l|}{ Tundra sites } \\
\hline Varandei & $68.49 \mathrm{~N}$ & $58.01 \mathrm{E}$ & 5 & coastal plain & $1940-2000$ & $x$ \\
\hline Khorei Ver & $67.25 \mathrm{~N}$ & $58.04 \mathrm{E}$ & 72 & flat & 1961-1995, s.g. & 1961-1995, s.g. \\
\hline Khoseda Khard & $67.05 \mathrm{~N}$ & $59.23 \mathrm{E}$ & 84 & upper river terrace & 1932-2000, s.g. & $1936-2000$, s.g. \\
\hline Vorkuta & $67.29 \mathrm{~N}$ & $64.02 \mathrm{E}$ & 165 & western flank of Urals & 1947-2007, s.g. & 1936-2007, b.g. \\
\hline Salekhard & $66.53 \mathrm{~N}$ & $66.67 \mathrm{E}$ & 16 & eastern flank of Urals & 1883-2007, s.g. & $\mathrm{x}$ \\
\hline \multicolumn{7}{|l|}{ Taiga sites } \\
\hline Troitsko Pechorsk & $62.42 \mathrm{~N}$ & $56.12 \mathrm{E}$ & 139 & flat & 1893-1998, s.g. & 1936-1993, s.g. \\
\hline Ust Usa & $65.58 \mathrm{~N}$ & $56.55 \mathrm{E}$ & 77 & flat & 1929-1998, s.g. & 1936-1998, s.g. \\
\hline Ust Shugor & $64.16 \mathrm{~N}$ & $57.37 \mathrm{E}$ & 73 & flat & 1896-1994, s.g. & $1936-1990$ \\
\hline Petrun & $66.26 \mathrm{~N}$ & $60.49 \mathrm{E}$ & 61 & flat & $1926-2000$ & 1936-2000, s.g. \\
\hline Ust Tsilma & $65.42 \mathrm{~N}$ & $52.28 \mathrm{E}$ & 68 & flat & $1896-2000$ s.q. & $1899-2000$, s.q. \\
\hline
\end{tabular}




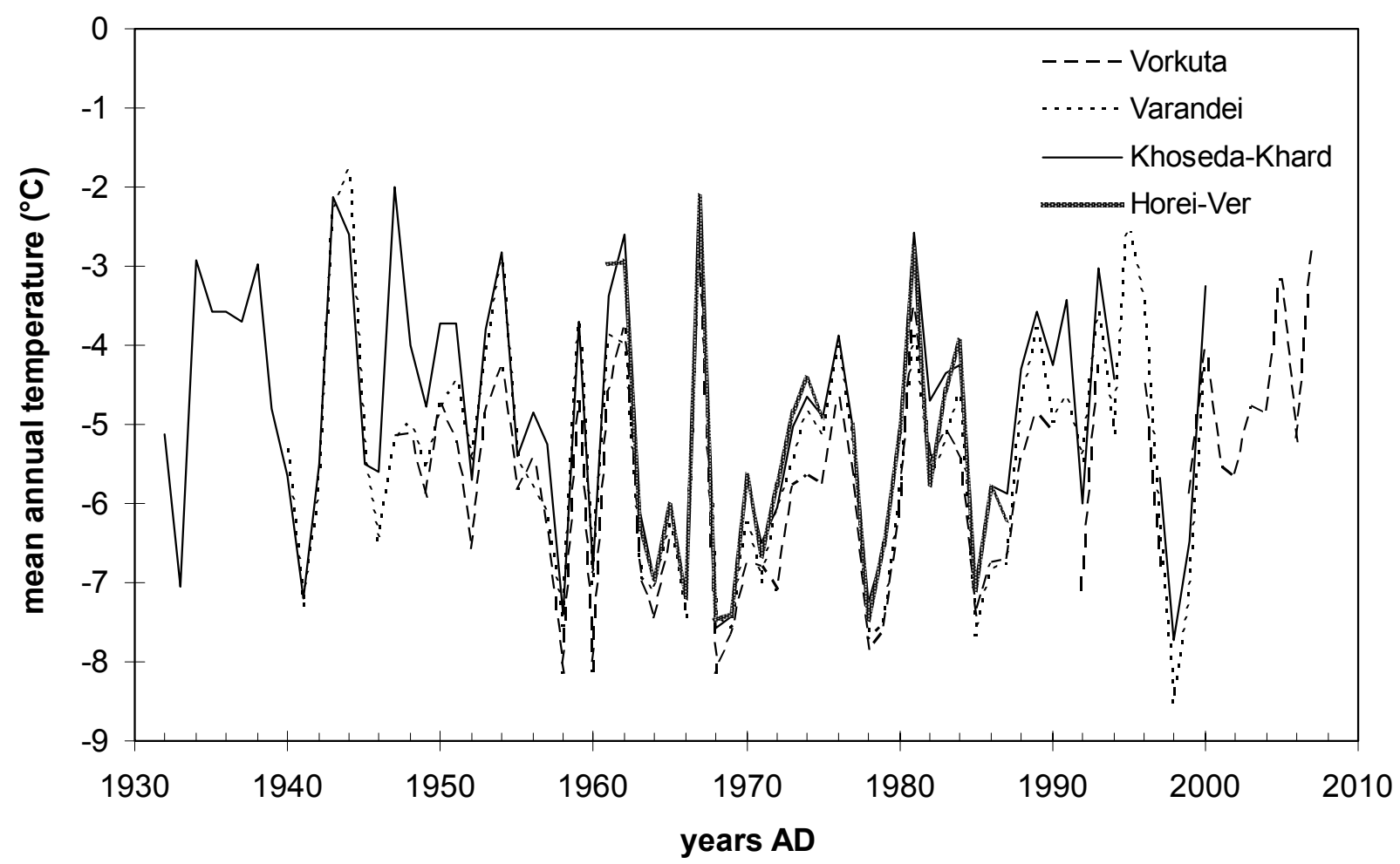

Fig. 3. Mean annual temperatures for the meteorological stations of Vorkuta, Varandei, Khoseda-Khard and Khorei-Ver.

partures from 1961-1990 mean) from the four tundra stations with an average from the five taiga weather stations and an additional weather station on the eastern flank of the Ural mountain chain (Salekhard) reveals that even at this larger spatial scale, the temperature pattern is very similar (Fig. 4). This holds true both for the long term temperature development as well as for the year-toyear variability and extreme values. Thus, it seems feasible to extend our record of observed temperature anomalies for the Moreju site back to 1883. An important parameter for tree growth in this extreme northern environment is the amount of snow that falls during the winter time. The snow cover can be approximated by the winter precipitation records from weather stations, i.e. the months from November to April, as the average temperatures during these months lies well below $0^{\circ} \mathrm{C}$. A comparison of monthly winter precipitation - often a difficult parameter to measure - with observed snow depth at the climate station of Khoseda Khard confirms that the winter snow cover is recorded with sufficient accuracy. The available record of winter precipitation, starting in 1936, from three climate stations in the vicinity of the Moreju River study site is shown in Fig. 5.

\section{Tree ring width}

Tree ring cross dating revealed that the investigated trees were growing from 1909-1991 (T1), 1844-1969 (T2), 1954-2003 (T4), 1905-1996 (T5) and 1830-1998 (16 Khoseda trees). The data from T1, T2 and T5 (Fig. 6) were combined and an index was calculated. Comparison of the Moreju index with the Khoseda and "Russia" indices confirms the chronology of the records (Fig. 7).

Although the data set from the Moreju trees is regarded as too small to derive a proper tree ring index with a robust palaeoclimatological significance, we analyzed the single tree ring curves as well as the combined index of all three trees from Moreju plus the Khoseda trees (separately) to see whether there are any correlations between the ring width and mean monthly temperature anomalies or precipitation changes from the current growth year or the year before. Results are summarized in Tables 2 and 3. A correlation between ring width and June and July temperatures and even with some winter months can be observed for some of the trees, but not for the combined calculated Moreju index. There are however significant anti-correlations on the $95 \%$ level with the precipitation of the previous winter months (November to April).

\section{Stable isotopes}

Isotope data were analyzed from four different trees: T2, T4, T5 and the oldest Khoseda tree. Carbon and oxygen isotope ratios $\left(\delta^{13} \mathrm{C}\right.$ and $\left.\delta^{18} \mathrm{O}\right)$ were measured for the years 1864-1969 (T2), 1979-2003 (T4), and 1905-1996 (T5), i.e. the youngest 20-25 years of T2 and T4 were omitted because of the known juvenile noise that is unrelated to climate or environmental conditions during the growth of the tree. The Khoseda tree was analyzed for $\delta^{13} \mathrm{C}$ for the years 1916-1988. There is no correlation between $\delta^{13} \mathrm{C}$ or $\delta^{18} \mathrm{O}$ and the age of individual trees (Fig. 8). Therefore, the stable isotope curves were not 


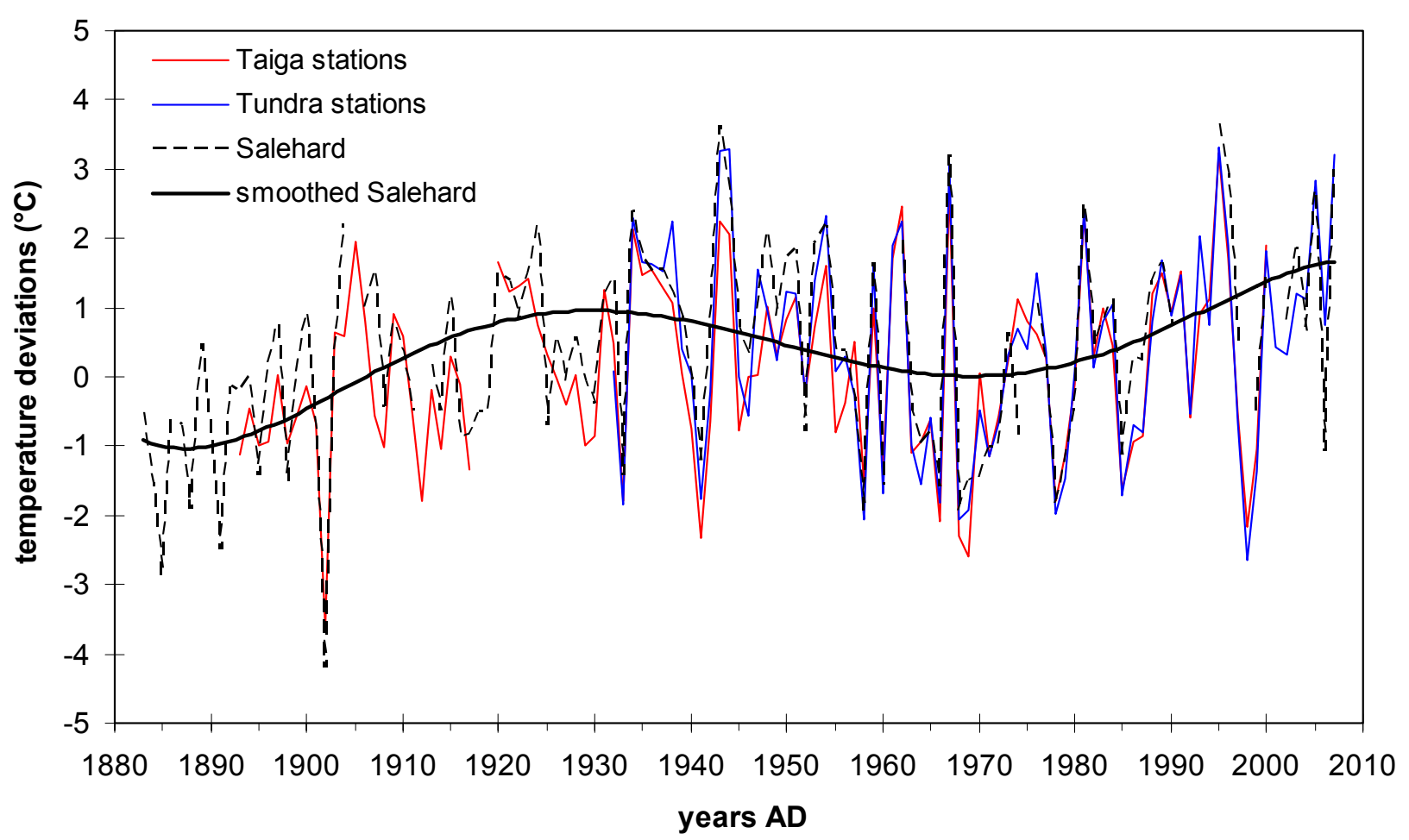

Fig. 4. Average annual temperature anomalies (deviations from 1961-1990 mean) of four tundra weather stations, five taiga weather stations and Salekhard (east of Urals).

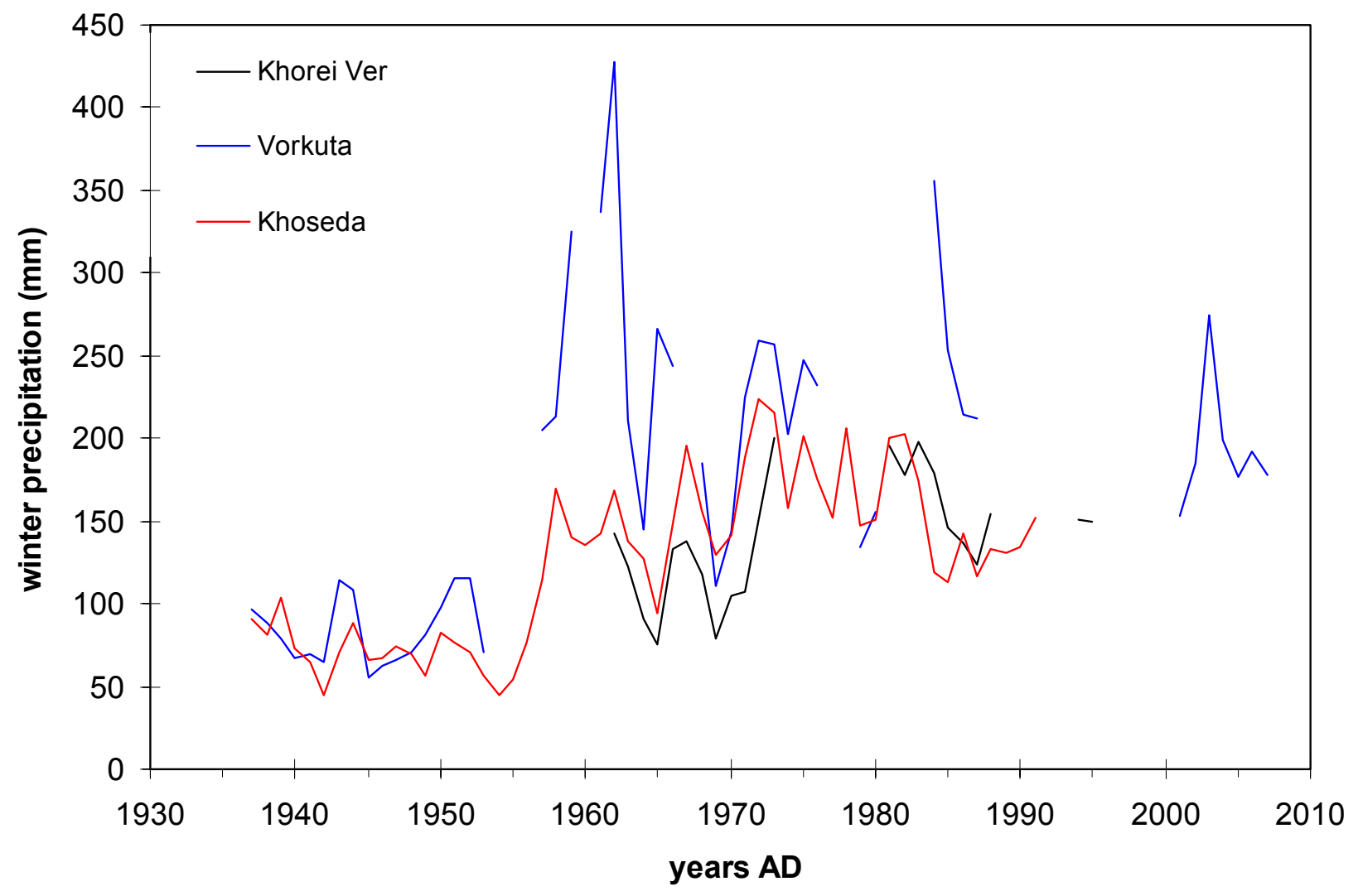

Fig. 5. Winter precipitation (November to April) from three tundra weather stations. 


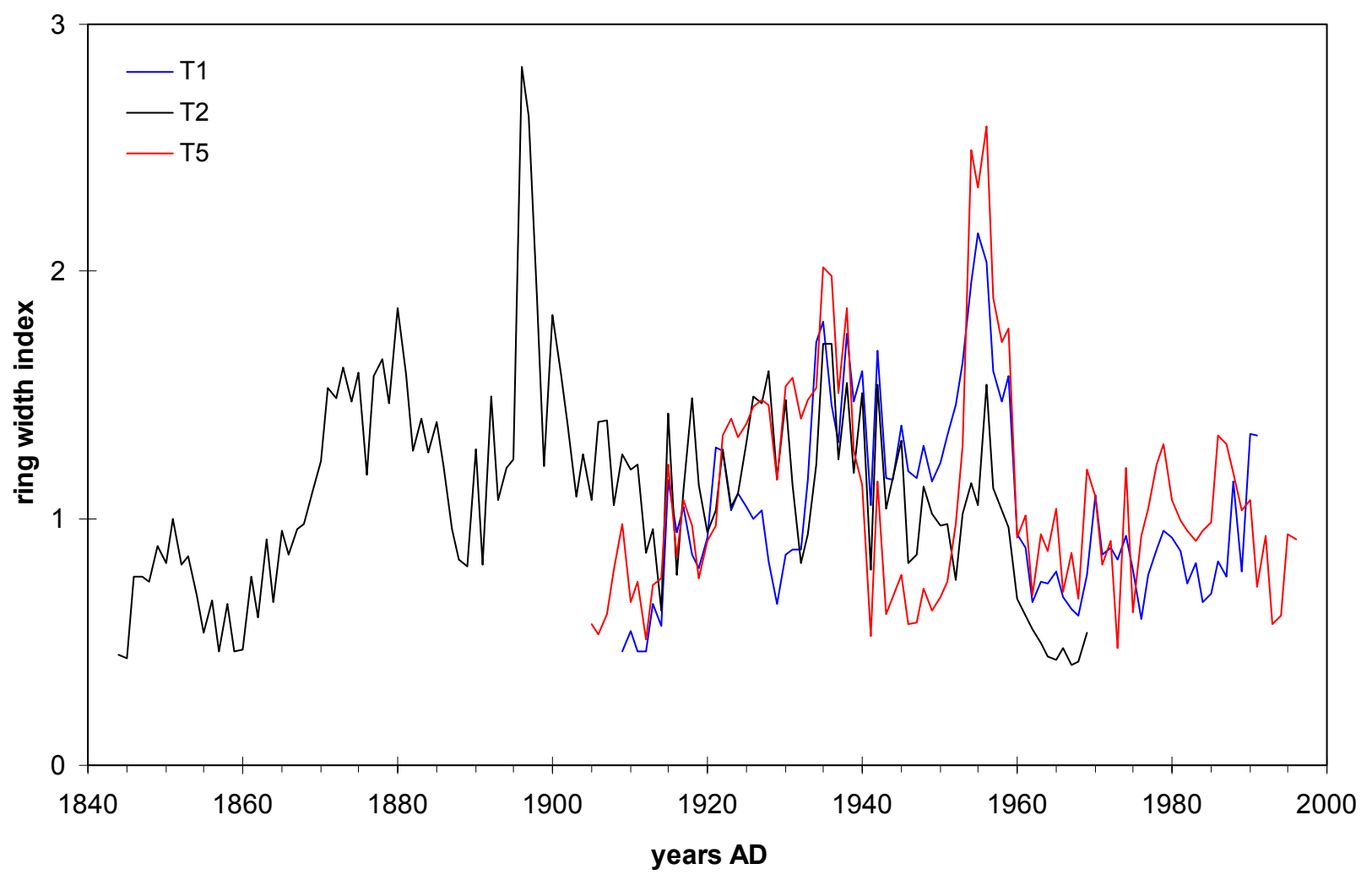

Fig. 6. Tree ring width indices from three trees $T 1, T 2$ and $T 5$ that were used to calculate a mean Moreju index.

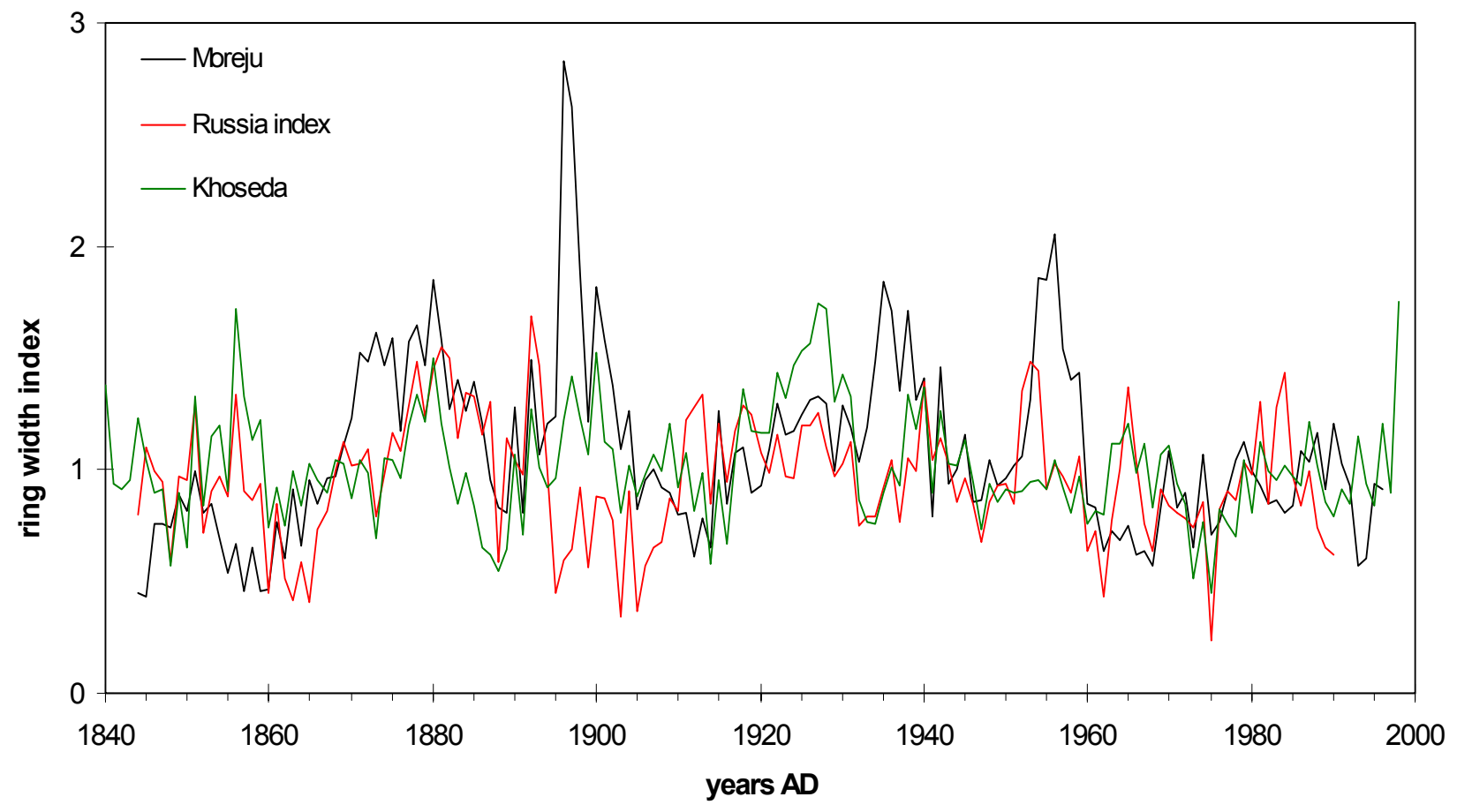

Fig. 7. Tree ring width indices from the Moreju trees, Khoseda trees and the "Russia" chronology. 


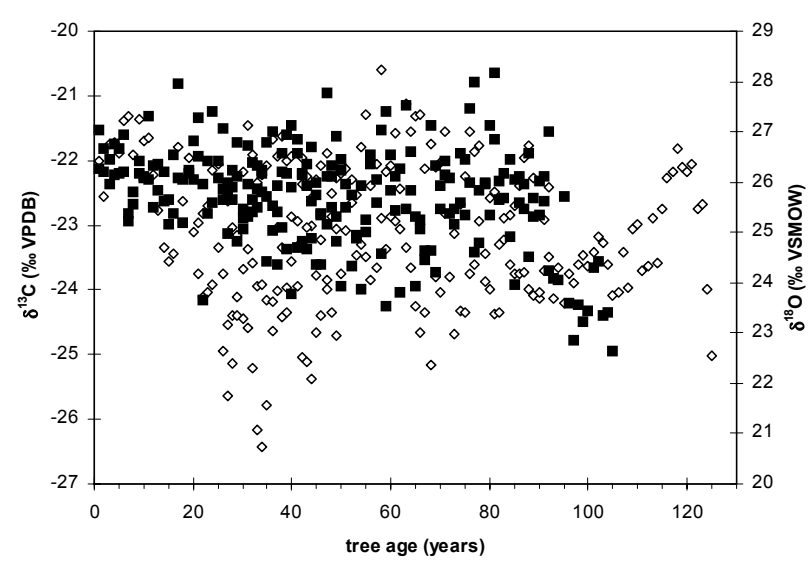

Fig. 8. $\delta^{13} \mathrm{C}$ (open diamonds) and $\delta^{18} \mathrm{O}$ (black squares) values versus age of individual tree rings in $T 1, T 2$ and $T 5$.

detrended as it has been done for the calculation of the ring width indices. The $\delta^{13} \mathrm{C}$ tree ring data were corrected for the decrease in atmospheric $\delta^{13} \mathrm{C}$ values due to the rise in $\mathrm{CO}_{2}$ caused by fossil fuel combustion since the beginning of the industrialization (Francey et al., 1999). The overlap with the observed meteorological data allowed a comparison of the isotope data with measured temperature and precipitation at the surrounding climate stations.

The $\delta^{13} \mathrm{C}$ curves from the analyzed Moreju and Khoseda trees show similar trends and periodically very similar features (Fig. 9). However, there are also clear differences. Whereas there is a good match between T2 and the Khoseda tree, there is a distinct offset between T2 and $\mathrm{T} 5$ by up to $3 \%$ in some periods. The Moreju carbon isotope data show an unclear pattern of correlation with temperature (Table 2). Whereas T2 shows a significant correlation with July air temperature, the correlation is significant for June in T4 and the Khoseda $\delta^{13} \mathrm{C}$ shows significant correlations with both months. A positive

Table 2. Correlation coefficients (95\%-confidence level) between ring width, $\delta^{13} \mathrm{C}, \delta^{18} \mathrm{O}$ and monthly air temperature.

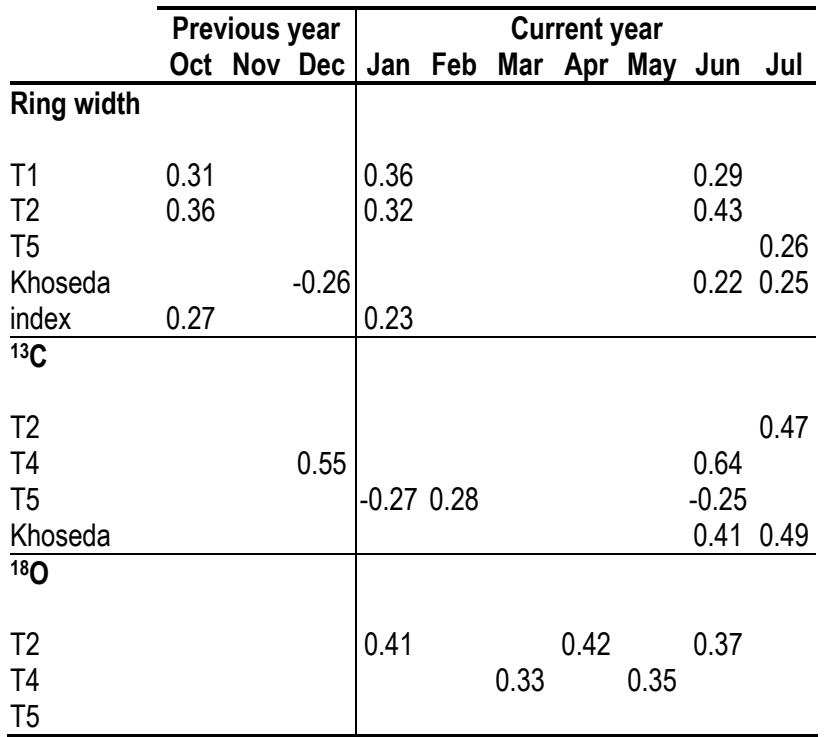

correlation between $\delta^{18} \mathrm{O}$ (Fig. 10) and temperature of different months can be observed, but the patchy distribution of the correlated months indicates that the influence of temperature is comparatively small (Table 2).

The precipitation of the previous winter months explains, however, a large portion of the observed variability in stable isotope values and correlation coefficients of around $-0.5\left(\delta^{18} \mathrm{O}\right)$ and $0.6\left(\delta^{13} \mathrm{C}\right)$ were calculated for the months November till February, particularly for tree T2 (Tables 2 and $\mathbf{3}$ ).

\section{DISCUSSION}

\section{Ring width}

The comparatively poor correlation between ring width data and the observed summer temperature indicates that growth season temperatures do not seem to have influenced the tree growth very much. Instead, it seems that the winter precipitation has a larger influence on the ring width. A likely explanation is that the depth of the snow cover influences the length of the growth season and with that the tree ring width. Regardless of the temperature, a thinner snow cover is more likely to melt away earlier than a thick snow cover and as a consequence, the new tree rings can start to develop earlier in spring and has more time to grow until the end of the growth season. The early summer months, May and June, are most critical for the wood formation and the melt timing has thus a strong impact on the ring width (Vaganov et al., 1999).

\section{Stable isotopes}

The $\delta^{18} \mathrm{O}$ and $\delta^{13} \mathrm{C}$ isotopes are an integrative proxy for the climatic and environmental conditions during the growth of the tree. Under temperate conditions, both isotopes are mainly related to the moisture conditions during the summer months (Treydte et al., 2007). In a study from southern Poland it was found that $\delta^{18} \mathrm{O}$ in tree

Table 3. Correlation coefficients (95\%-confidence level) between ring width, $\delta^{13} \mathrm{C}, \delta^{18} \mathrm{O}$ and monthly precipitation.

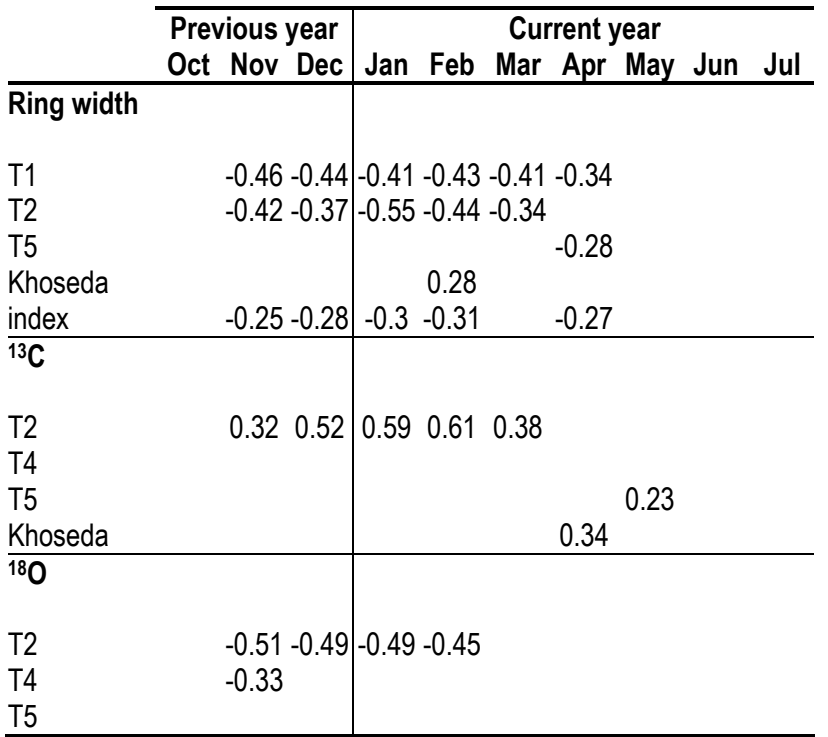




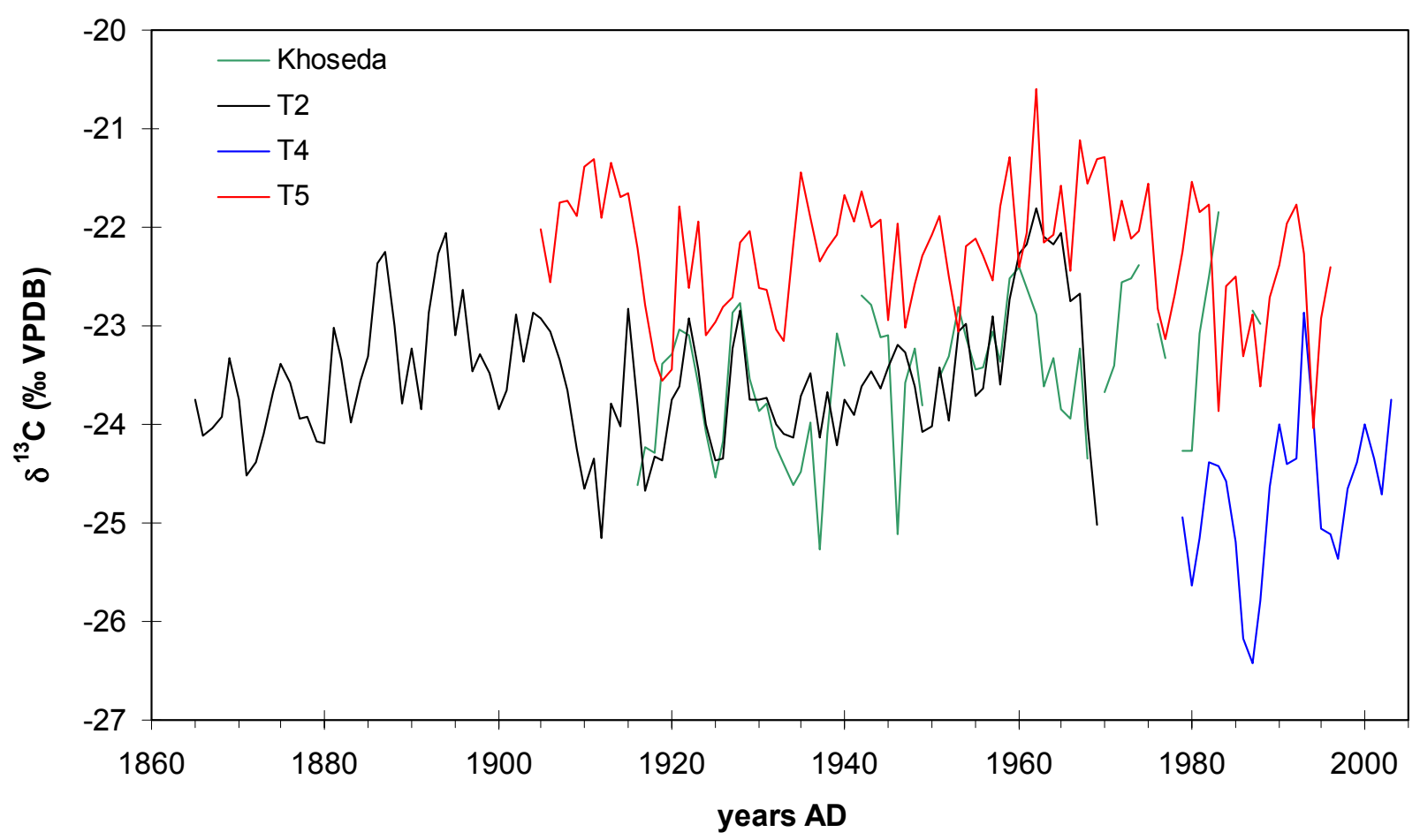

Fig. 9. $\delta^{13} \mathrm{C}$ data from three trees from Moreju and one tree from Khoseda.

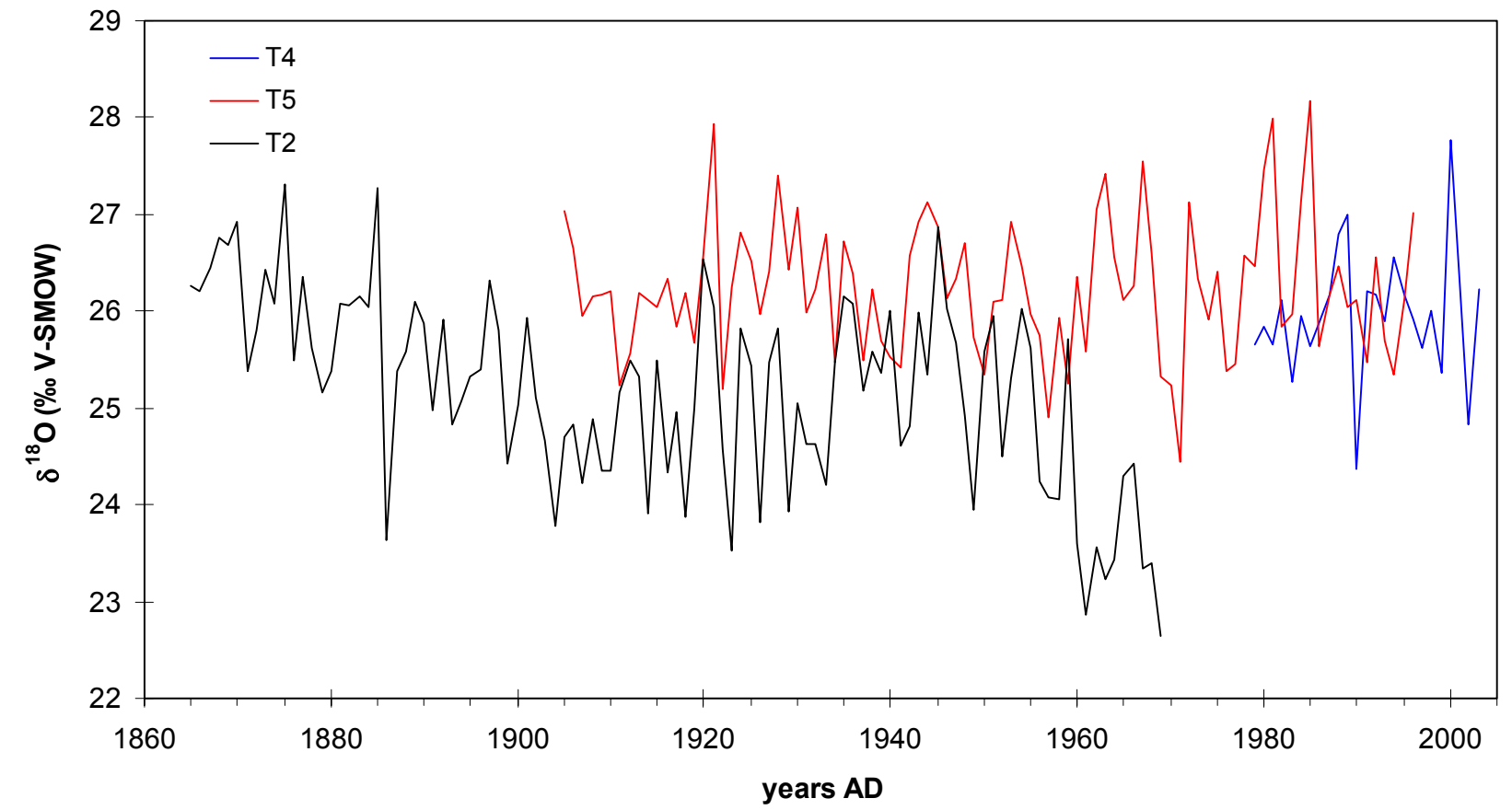

Fig. 10. $\delta^{18} \mathrm{O}$ data from three analyzed trees from Moreju.

rings from pine are correlated with the amount of summer precipitation and sunshine (Szczepanek et al., 2006). Thus, it is crucial to interpret the isotope values by evaluating their relationship with observed climate data for each region to understand the underlying mechanisms. The $\delta^{13} \mathrm{C}$ isotope value of tree ring cellulose is controlled by the difference between the intercellular and ambient atmospheric $\mathrm{CO}_{2}$ concentrations (McCarroll and Loader,
2004). In other words, the carbon isotope composition in tree rings depends on the rate of photosynthesis (carboxylation) and stomatal conductance. This can be caused by a number of parameters, amongst which air humidity, temperature and soil moisture status are probably the most important ones.

The Moreju and Khoseda $\delta^{13} \mathrm{C}$ data series show partly large offsets between individual trees (Fig. 9). This might 
be due to the wide range of parameters that control the stomatal conductance of the needles in trees that grow under different soil moisture and microclimatic conditions. However, common trends and patterns can still be identified, especially in T2 and the Khoseda tree. The $\delta^{13} \mathrm{C}$ values of $\mathrm{T} 4$ and the Khoseda tree show a positive correlation with June temperature, T2 and the Khoseda tree with July temperature. In the case of tree T2, the amount of precipitation fallen in the previous winter months seems to be a more important influence factor for the $\delta^{13} \mathrm{C}$ of the ring cellulose than summer temperature, as revealed by the high correlation coefficients of all months from November to March.

The $\delta^{18} \mathrm{O}$ value of tree rings depends on the oxygen isotope ratio in the source water (i.e. precipitation), including recycling of moisture from the landscape, cloud track and fallout histories of the water vapour reaching the site and the temperature during the precipitation event (Kohn and Welker, 2005), as well as on additional processes in the soil zone and in the tree. Evaporation in the soil water and transpiration on the needles, for example, leads to an enrichment of ${ }^{18} \mathrm{O}$ relative to ${ }^{16} \mathrm{O}$. Thus there is a similarly large variety of processes as for the carbon isotopes that can contribute to the final $\delta^{18} \mathrm{O}$ values in the ring cellulose.

There is no clear match between the $\delta^{18} \mathrm{O}$ isotope curves of the analyzed trees from Moreju (Fig. 10). This could be the result of the different hydrological conditions under which the trees were growing. Whereas T4 was growing on a lower terrace of the Moreju River and probably was influenced by the river water, T1 and T2 were located on a high and steep river bank, $\sim 3 \mathrm{~m}$ above the water level at the time of sampling. Thus it can be assumed that the $\mathrm{T} 1$ and $\mathrm{T} 2$ trees were primarily fed by water derived by snow melt and direct precipitation rather than by the river. The sensitivity of the isotopes to the thickness of snow cover can thus be expected to be higher for T1 and T2 compared to T4. As T5 was collected downstream and was obviously transported by the river, its original position in the landscape is unknown. After evaluating the relationship between $\delta^{18} \mathrm{O}$ and observed temperature and precipitation it can be concluded that there is some correlation of oxygen isotope values with late winter to early summer temperatures and a clear negative correlation with winter precipitation (NovemberFebruary). It is likely that winters with a thick snow cover with low $\delta^{18} \mathrm{O}$ values will result in relatively depleted $\delta^{18} \mathrm{O}$ values of the soil moisture which will be incorporated into the ring cellulose.

Considering the (anti-) correlations of $\delta^{18} \mathrm{O}$ and $\delta^{13} \mathrm{C}$ in the tree ring cellulose with the amount of winter precipitation, the isotope curves can be utilized to reconstruct winter precipitation over the time period covered by the tree ring isotope data. Accordingly, we interpret the trends in oxygen and carbon isotopes in such way that the period from 1865-1900 was characterized by increasing winter precipitation, followed by a period with slightly decreasing snow fall until $\sim 1930$. After that, the precipitation amount increased again until a maximum was reached in $\sim 1965$. Since then, winter precipitation was decreasing again and remained stable after $\sim 1990$.

\section{CONCLUSIONS}

The stable oxygen and carbon isotope data from the analyzed trees differ in their degree of correlation with observed monthly precipitation and temperature, and also the absolute isotope values between the trees are partly offset. This indicates that site specific factors, such as soil moisture availability, drainage capacity of the ground, ground water and microclimatic conditions play an important role and determine whether the isotopes are an indicator of temperature or precipitation, or a mixture of the two.

However, interpreting the isotope curves of single specimen can be a tool to reconstruct changes of climatic and environmental conditions, as revealed by partly high correlations with observed climate. The advantage of the isotopes over the ring width data is the absence of the biologically induced aging trend that disturbs the low frequency climate signal from the ring width curves, and that additional climate parameters can be reconstructed, such as winter precipitation and snow cover. However, the complexity of processes that influence the isotope composition of the ring cellulose is large and requires better understanding. More isotope data from tree rings will help to shed light on the underlying processes, but also modelling approaches and data from other climate archives from the same region, such as lake sediments and peat, need to be studied to decipher the different mechanisms acting on different temporal and spatial scales.

\section{ACKNOWLEDGEMENTS}

We thank Anna Pazdur and an anonymous reviewer for constructive comments on the earlier version of the manuscript. The study was financed by the EU-CARBONorth Project (contract 036993), EU-GLIMPSE Project (contract EVK2-CT-2002-00164) and EU-TUNDRA Project (contract ENV4-CT97-0522).

\section{REFERENCES}

Biondi F and Waikul K, 2004. DENDROCLIM2002: a C++ program for statistical calibration of climate signals in tree-ring chronologies. Computers and Geosciences 30(3): 303-311, DOI 10.1016/j.cageo.2003.11.004.

Briffa KR, 1995. Unusual twentieth-century summer warmth in a 1,000year temperature record from Siberia. Nature 376(6536): 156-159, DOI $10.1038 / 376156 \mathrm{a} 0$.

Briffa KR, Shishov VV, Melvin TM, Vaganov EA, Grudd H, Hantemirov RM, Eronen $M$ and Naurzbaev MM, 2008. Trends in recent temperature and radial tree growth spanning 2000 years across Northwest Eurasia. Philosophical Transactions of the Royal Society of London B 363: 2271-2284. DOI 10.1098/rstb.2007.2199.

Francey RJ, Allison CE, Etheridge DM, Trudinger CM, Enting IG, Leuenberger M, Langenfelds RL, Michel E and Steele LP, 1999. A 1000-year high precision record of $\delta^{13} \mathrm{C}$ in atmospheric $\mathrm{CO}_{2}$. Tellus B 51(2): 170-193, DOI 10.1034/j.1600-0889.1999.t01-100005.x.

Harding R, Kuhry P, Christensen TR, Sykes MT, Dankers R and van der Linden S, 2002. Climate feedbacks at the tundra-taiga interface. Ambio Special Report 12: 47-55.

Holmes RL, Adams RK and Fritts HC, 1986. Tree-ring chronologies of western North America: California, eastern Oregon and northern Great Basin, with procedures used in the chronology development work, including user manuals for computer programs COFECHA 
and ARSTAN. Laboratory of Tree-Ring Research, University of Arizona, Tucson Chronology Series VI: 50-65.

IPCC, 2007. Summary for Policy Makers. IPCC Special Report: $16 \mathrm{pp}$.

Kohn MJ and Welker JM, 2005. On the temperature correlation of $\delta^{18} \mathrm{O}$ in modern precipitation. Earth and Planetary Science Letters 231(1-2): 87-96 DOI 10.1016/j.epsl.2004.12.004.

Loader NJ, Robertson I, Barker AC, Switsur VR and Waterhouse JS, 1997. An improved technique for the batch processing of small wholewood samples to $\alpha$-cellulose. Chemical Geology 136(3-4): 313-317 DOI 10.1016/S0009-2541(96)00133-7.

McCarroll D and Loader NJ, 2004. Stable isotopes in tree rings. Quaternary Science Reviews 23(7-8): 771-801 DOI 10.1016/j.quascirev.2003.06.017.

Szczepanek, M, Pazdur, A, Pawelczyk, S, Boettger, T, Haupt, M, Halas, S, Bednarz, Z, Krapiec, M and Szychowska-Krapiec, E, 2006. Hydrogen, carbon and oxygen isotopes in pine and oak tree rings from Southern Poland as climatic indicators in years 1900-2003. Geochronometria 25: 67-76.

Treydte, K S, Frank, D, Esper, J, Andreu, L, Bednarz, Z, Berninger, F, Boettger, T, D'Alessandro, C, Etien, N, Filot, M, Grabner, M, Guillemin, M, Guttierez, E, Haupt, M, Helle, G, Hilasvuori, E, Jungner, H, Kalela-Brundin, M, Krapiec, M, Leuenberger, M, Loader, N J, Masson-Delmotte, V, Pazdur, A, Pawelczyk, S, Pierre, M, Planells, O, Pukiene, R, Reynolds-Henne, C, Rinne, K T, Saracino, A, Saurer, M, Sonninen, E, Stievenard, M, Switsur, V R, Szczepanek, M, Szychowska-Krapiec, E and Todaro, L, 2007. Signal strength and climate calibration of a European tree-ring isotope network. Geophysical Research Letters 34(L24302): DOI 10.1029/2007GL031106.

Vaganov EA, Hughes MK, Kirdyanov AV, Schweingruber FH and Silkin PP, 1999. Influence of snowfall and melt timing on tree growth in subarctic Eurasia. Nature 400(6740): 149-151, DOI $10.1038 / 22087$ 